\title{
Cleft Lip/Nasal Deformities After Plastic Surgery for Unilateral Cleft Lip/Palate: A Prospective Study at a Large Hospital in Vietnam
}

\author{
Hong Loi Nguyen (D)' \\ Van Minh Nguyen ${ }^{2}$ \\ Xuan Phu Tran' \\ 'Odonto-Stomatology Center, Hue \\ Central Hospital, Hue City, Vietnam; \\ ${ }^{2}$ Faculty of Odonto-Stomatology, Hue \\ University of Medicine and Pharmacy, \\ Hue University, Hue City, Vietnam
}

Correspondence: Hong Loi Nguyen Odonto-Stomatology Center, Hue Central Hospital, 16 Le Loi street, Hue City, 530000, Vietnam

Tel +84913498549

Email drloivietnam@yahoo.com.vn
Introduction: Congenital cleft lip, with or without cleft palate, is the most common deformity of the face. Primary plastic surgery for rehabilitation and esthetics is important for patients and their parents; however, secondary deformities of the lip and nose can occur after the primary surgery. Therefore, we performed assessment of secondary cleft lip/nasal deformities to aid in planning of surgical repair of these deformities.

Materials and Methods: Forty-six patients with unilateral cleft lip, with or without cleft palate, were operated with different techniques and examined post-surgery at the Department of Maxillofacial Surgery, University of Medicine and Pharmacy Hospital and Center of Odonto-Stomatology, Hue Central Hospital. They were assessed according to Motier's post-operative evaluation scale (1997), including the red lip, white lip, scars, and nose.

Results: V notch and defect on the shift line were the most common deformities on the red lip (52.2\%). About $34.8 \%$ of the patients had a short white lip on the cleft side. Straight and prominent scars were observed in $52.2 \%$ of the patients. The most common deformities of the nose were septal deviation $(78.3 \%)$, followed by defects in the upper part of the nostril contour (78.3\%), narrow sill (52.2\%), and low position of the ala (47.8\%).

Conclusion: Secondary cleft lip/nasal deformities are unavoidable. It is necessary to develop a plan for surgical repair of these deformities. There is no single method of cleft lip surgery that gives perfect results. Therefore, clinicians choose a combination of methods to bring optimal results for each patient.

Keywords: unilateral, cleft lip/palate, secondary deformities

\section{Introduction}

Cleft lip is a common congenital deformity of the jaw. National and international authors have reported the rate of cleft lip to be approximately 3/10,000 lives birth. ${ }^{1}$ The different types of cleft lip cause changes in anatomical structure, greatly affecting the function and esthetics of the face and impacting the psychology of patients from childhood to adulthood. Lip/nasal plastic surgery to restore function and esthetics is important for patients and their families. Many methods of cleft lip plastic surgery have been proposed and improved.

However, lip/nasal deformities after cleft lip plastic surgery occurs in approximately $70-80 \%$ of patients; the extent of the deformities can vary depending on many different factors, such as the cleft's morphology and the varied qualification of surgeons. ${ }^{2}$ 
Millard D. R. (1976), observed that most patients after cleft lip primary surgery required follow-up and repair with secondary surgery. Milliken et al reported that there are no methods that have been able to achieve complete results with the first surgery. ${ }^{3}$

A secondary surgery to repair lip/nasal deformities for esthetics and functional completion after the primary cleft lip plastic surgery is increasingly being proposed. We carried out this study to evaluate lip/nasal deformities after primary plastic surgery in patients with unilateral cleft lip/palate to aid in surgical planning for the secondary surgery.

\section{Materials and Methods}

This prospective study was conducted from January 2018 to December 2019 with the approval of the Hue Central Hospital ethics committee (IEC number: 08-2018/NCKHBVH). We enrolled 46 patients with lip/nasal deformity after primary lip plastic surgery for unilateral cleft lip at the Inter-Specialized Department OtorhinolaryngologyOphthalmology-Odonto-stomatology, Hue University of Medicine and Pharmacy Hospital, and Odontostomatology Center, Hue Central Hospital.

The timing of scar assessment after surgery depends on the type of scar: bad scars are assessed after 6-12 months. As for the evaluation of stretching ones that deform lips, 24 months are indicated. After that, the patient will be reexamined every 6 months.

The inclusion criteria were patients with a unilateral cleft lip who had undergone primary lip plastic surgery and whose lip/nasal deformities had not yet been repaired. Exclusion criteria were (1) cleft lip patients associated with other maxillofacial congenital malformations and (2) patients or families who did not agree to participate in the study.

Study objectives included (1) Classification of cleft lip into cleft lip, cleft lip arch, and cleft lip palate by Kernahan Striped Y classification. ${ }^{4}$ (2) Determination of methods of primary plastic surgery for unilateral cleft lip according to Millard et al. (3) Evaluation of lip/nasal deformities after unilateral cleft lip plastic surgery by Motier's post-operative evaluation scale $(1997)^{5}$ (Table 1) with the illustrated images in Figure 1Figure 2Figure -3 .

Next, we calculated the total score and classified the results according to Table 2 .

All qualitative data was analyzed statistically using SPSS version 16.0 (SPSS Inc., Chicago, IL, USA) and
Table I Evaluation of Lip/Nasal Deformity After Unilateral Cleft Lip Plastic Surgery

\begin{tabular}{|c|c|c|}
\hline $\begin{array}{l}\text { Anatomical } \\
\text { Factors }\end{array}$ & Evaluation & Point \\
\hline Red lip & $\begin{array}{l}\text { Convex/Keloid } \\
\text { V-notch } \\
\text { Unilateral thickening of lip } \\
\text { Unilateral thinning of lip } \\
\text { Deviation of lip contour }\end{array}$ & $\begin{array}{l}0.5 \\
0.5 \\
1 \\
3 \\
0.5\end{array}$ \\
\hline Vestibular groove & $\begin{array}{l}\text { Narrow } \\
\text { Too wide }\end{array}$ & $\begin{array}{l}1 \\
2\end{array}$ \\
\hline Labial skin (White lip) & $\begin{array}{l}\text { Too short } \\
\text { Too long } \\
\text { M. orbicularis oris deficit } \\
\text { Narrow Cupid's bow and philtrum } \\
\text { Wide Cupid's bow and philtrum }\end{array}$ & $\begin{array}{l}1 \\
1 \\
3 \\
4 \\
2\end{array}$ \\
\hline Scar & $\begin{array}{l}\text { Good } \\
\text { Contracture } \\
\text { Keloid }\end{array}$ & $\begin{array}{l}0 \\
1 \\
1\end{array}$ \\
\hline Nose & $\begin{array}{l}\text { Short columella } \\
\text { Septal deviation } \\
\text { Wide nostril } \\
\text { Narrow nostril } \\
\text { Subnasale too wide } \\
\text { Subnasale too narrow } \\
\text { Slight curl of ala of nose } \\
\text { Excessive curl of ala of nose } \\
\text { Defect in superior nostril contour } \\
\text { High subnasale } \\
\text { Low subnasale } \\
\text { Hypotrophic and flat ala of nose }\end{array}$ & $\begin{array}{l}0.5 \\
2 \\
0.5 \\
0.5 \\
0.5 \\
0.5 \\
0.5 \\
0.5 \\
0.5 \\
0.5 \\
0.5 \\
3\end{array}$ \\
\hline
\end{tabular}

expressed as percentages. Chi-square test was used for testing relationships between the results of the first cleft lip surgery and methods. The statistical significance was set at $\mathrm{p}<0.05$.

\section{Results}

The red lip deformities are shown in Table 3. The most common deformities were $\mathrm{V}$-notch in the red lip and lip contour deviation, accounting for $52.2 \%$. Other deformities recorded in the red lips were unilateral thickening (2/ 46 patients) and unilateral lip thinning (4/46 patients), while no patients had keloid or vestibular groove deformity (Figure 4).

Among the 46 patients who underwent primary lip/ nose plastic surgery, lip skin was too short in 16 patients (34.8\%) (Figure 5); there were no other deformities such 

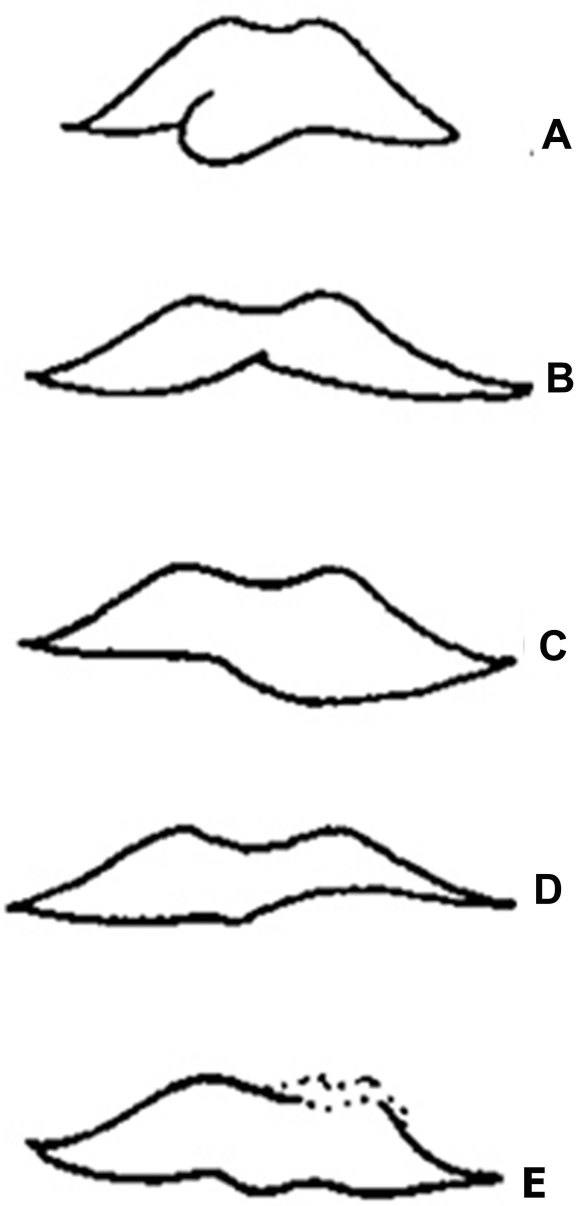

A
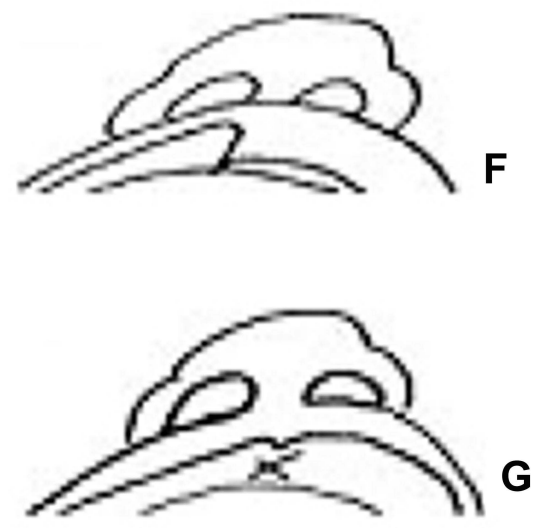

Figure I Evaluation of red lip ((A) Convex/Keloid; (B) V-notch; (C) Unilateral thickening of lip; (D) Unilateral thinning of lip; (E) Deviation of lip contour) and vestibular groove ((F) Narrow; (G) Too wide).

as M. orbicularis oris deficit and too narrow or too wide Cupid's bow and philtrum (Table 4). Majority of the patients $(47.8 \%, 22 / 46$ patients) had good scars, $21.7 \%$ had contracture scars (10/46 patients), and 30.5\% had keloids (14/46 patients) (as shown in Table 5 with the illustrated images in Figure 6).

The nasal deformities are shown in Table 6. The most common deformities were nasal septal deviation and defects on the edge of the nostril in 36/46 patients (78.3\%) each. The nostrils were narrow in 24/46 patients $(52.2 \%)$, the alae of the nose were less curled in $16 / 46$ patients $(26.1 \%)$, and the alae of the nose was low in 22/46 patients (47.8\%). Furthermore, 6/46 patients had short columella, 4/46 patients had high ala of the nose, and 2/ 46 patients had hypertrophic and flat ala of the nose. Deformities such as narrow nostrils, abnormal width of subnasale, and excessively curled ala of the nose were not present in any patient. Table 7 shows the results of the first cleft lip surgery and methods (Figure 7).

\section{Discussion}

\section{Red Lip Deformity}

We found that V-notch deformity accounted for a high rate of $52.2 \%$ of the red lip deformities, which is equivalent to the research results of Rajanikanth et al, which was $55 \%{ }^{6}$ However, the study by Cheema and Asim (2014) gave higher results $(66 \%)^{7}$

$\mathrm{V}$-notch deformity occurs because the muscles are not completely released during surgery; hence, they would be stretched when closed after surgery and the incision can lead to the $\mathrm{V}$-notch. Other causes include poor muscle stitch technique, asymmetric muscle connection, or even subcutaneous stitching without muscle stitching, leading to a concave lining of the red lip. 
Nguyen et al

Dovepress

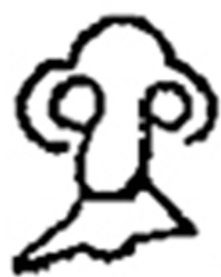

A
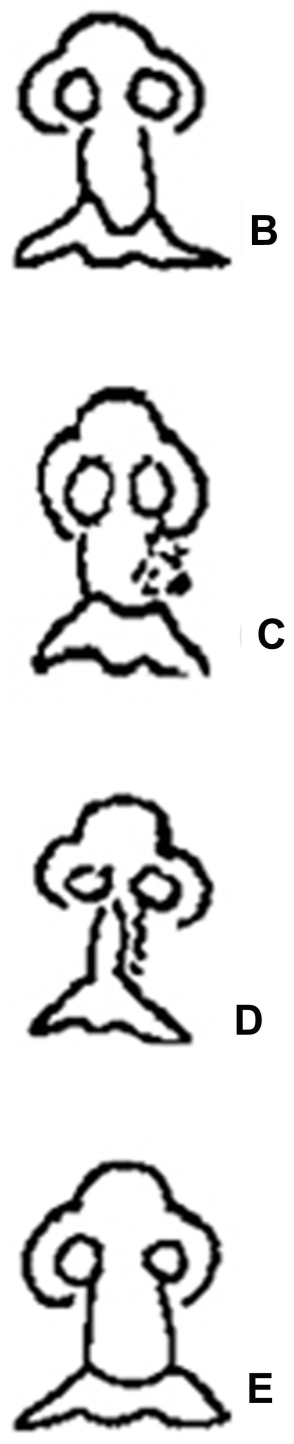

Figure 2 Evaluation of labial skin (White lip) ((A) Too short; (B) Too long; (C) M. orbicularis ores deficit; (D) Narrow Cupid's bow and philtrum; (E) Wide Cupid's bow and philtrum) and scar ((F) Good; (G) Contracture; $(\mathbf{H})$ Keloid).

Another common deformity is lip contour deviation, which is the protrusive formation of skin invading the red lips or the red lips invading the skin. In our study, this defermity appeared in 24 patients ( $52.2 \%$ ), which is higher than that
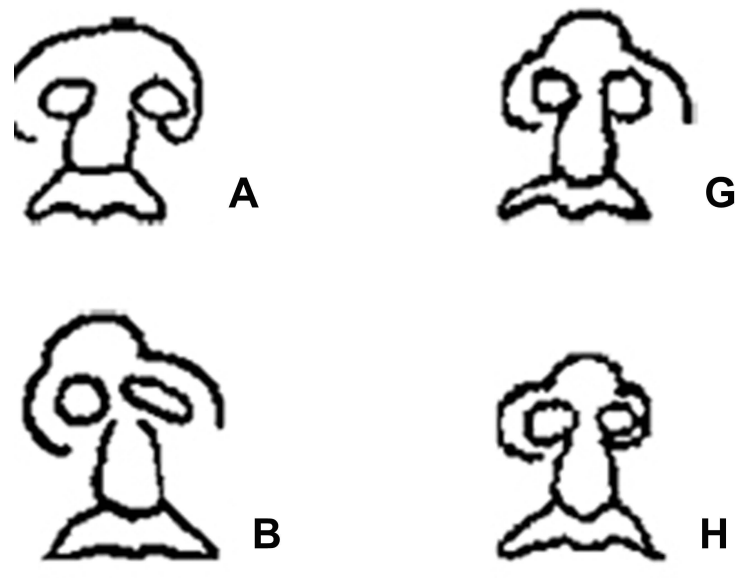

B
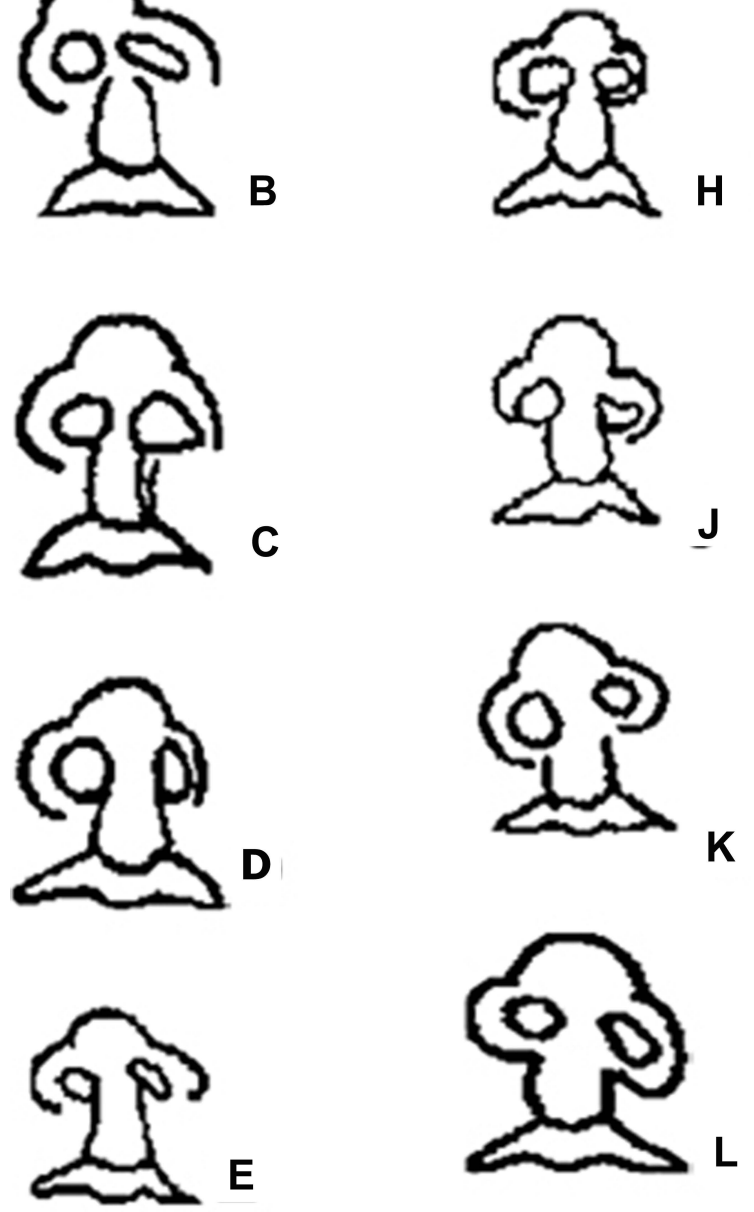

K

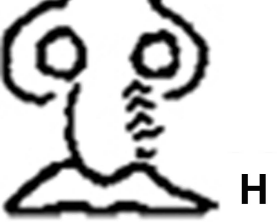

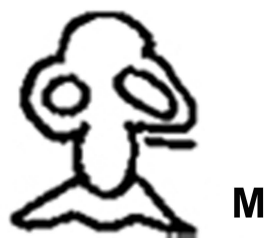

Figure 3 Evaluation of nose. (A) Short columella; (B) Septal deviation; (C) Wide nostril; (D) Narrow nostril; (E) Subnasale too wide; (F) Subnasale too narrow; (G) Slight curl of ala of nose; $(\mathbf{H})$ Excessive curl of ala of nose; $(\mathbf{J})$ Defect in superior nostril contour; (K) High subnasale; (L) Low subnasale; (M) Hypotrophic and flat ala of nose.

reported by Rajanikanth et al (30\%). ${ }^{6}$ However, Christofides et al reported a high rate of lip contour deviation $(65 \%){ }^{8}$

308

https://doi.org// 0.2147/CCIDE.S320636

Clinical, Cosmetic and Investigational Dentistry 2021:13

Dove Press 
Table 2 Classification of Surgery Results

\begin{tabular}{|l|l|}
\hline Classification & Point \\
\hline Excellent & $0-1.5$ \\
Very good & $2-3.5$ \\
Good & $4-5.5$ \\
Acceptable & $6-8$ \\
Difficult to accept & $8.5-16$ \\
\hline
\end{tabular}

Table 3 Red Lip Deformities

\begin{tabular}{|l|l|l|}
\hline Feature & $\begin{array}{l}\text { Number of } \\
\text { Patients }(\mathbf{n}=\mathbf{4 6})\end{array}$ & Percentage (\%) \\
\hline Keloid & 0 & 0 \\
V-notch & 24 & 52.2 \\
Unilateral thickening lip & 2 & 4.3 \\
Unilateral thinning lip & 4 & 8.7 \\
Deviation of lip contour & 24 & 52.2 \\
\hline
\end{tabular}

Lip contour deviation can be avoided by carefully marking the lip contour before surgery. Marking two points, one point above and one point below the lip contour, makes it easier to adjust and accurately stitch the incision rather than marking only one point at the red lip-skin contour.

\section{Features of Lip-Skin Deformity}

From Table 8, it can be seen that in all three studies, the rate of the lack of lip height is much higher than the excess. This is also a statement by many surgeons worldwide. ${ }^{9,10}$ In our study, the lip was too short in $34.8 \%$, equivalent to that reported by Rajanikanth et al, but lower than that reported by Cheema SA and Asim M (63\%). ${ }^{6,7}$

In patients with unilateral cleft lip, the short lip is often due to the selection of surgical methods that are not suitable for the type of cleft, such as the straight incision method or the rotation and advancement flap (incorrect rotation and advancement). In addition, it depends on the type of cleft. The wider the cleft, in coordination with the palate cleft, the higher the rate of deficiency of labial skin after surgery. In the 8 patients with short lips in our study
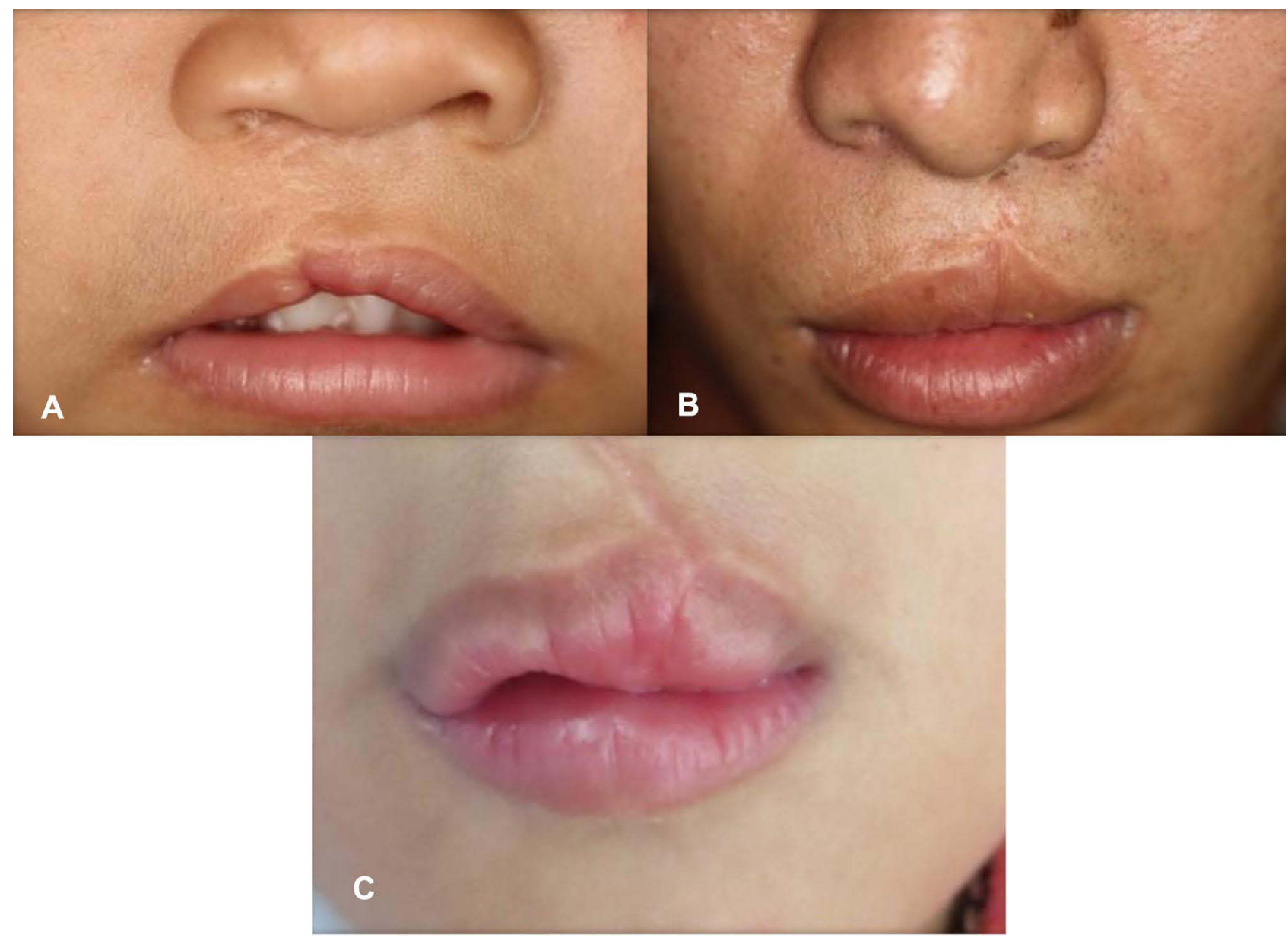

Figure 4 These images illustrate red lip deformities. (A) Convex and Deviation of lip contour, (B) Deviation of lip contour, (C) Unilateral thickening of lip. 


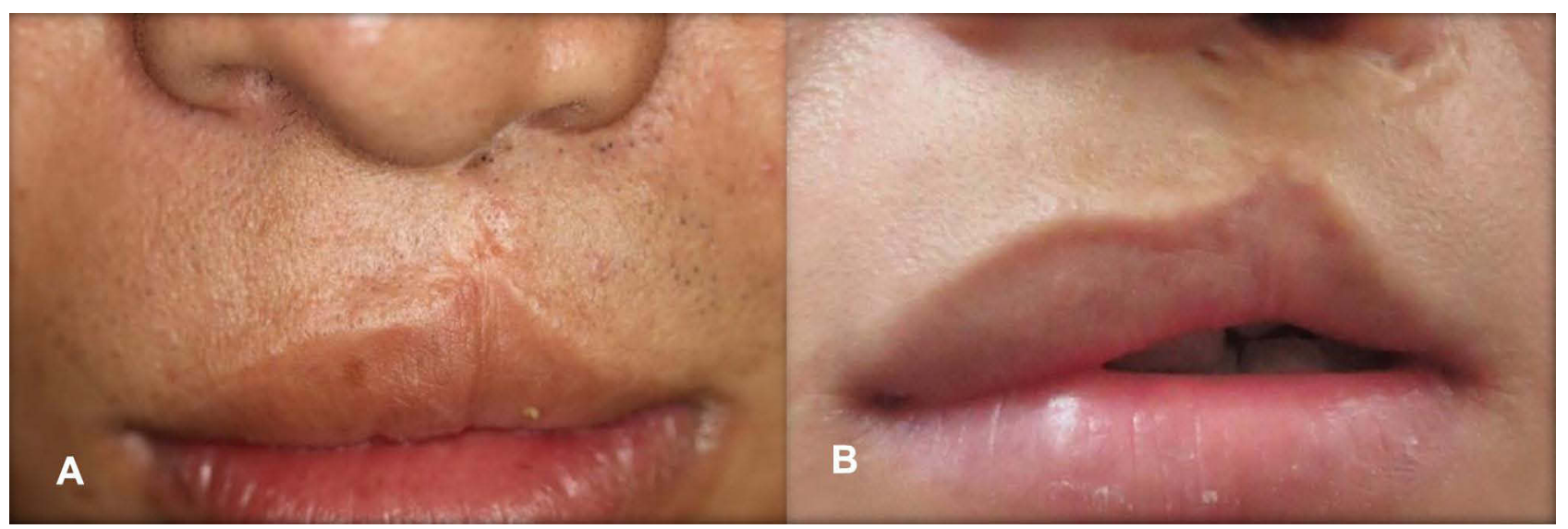

Figure $\mathbf{5}$ These images (A and $\mathbf{B}$ ) illustrate too short lip skin deformities.

sample, we found that 4 patients were treated by the Tennison method and 4 by the Millard method.

Zaleckas et al also used this scale to survey 66 patients with cleft lip surgery; however, their results showed that the lip skin score of the Millard method was significantly higher than that of the Tennison method. They explained that it was because surgeons were not familiar with the Millard method. ${ }^{11}$ Therefore, in addition to choosing the right surgical method, it is evident that the experience of the surgeon is very important to obtain satisfactory results of the lip length.

\section{Scars}

From the three studies in Table 9, it is evident that the rate of unfavorable scars differed by approximately $30 \%-70 \%$. In

Table 4 Lip Skin Deformities

\begin{tabular}{|l|c|c|}
\hline Feature & $\begin{array}{c}\text { Number of } \\
\text { Patients (n=46) }\end{array}$ & Percentage (\%) \\
\hline Too short & 16 & 34.8 \\
Too long & 0 & 0 \\
M. orbicularis oris deficit & 0 & 0 \\
Narrow cupidon bow and & 0 & 0 \\
philtrum & 0 & 0 \\
Wide cupidon bow and & & \\
philtrum & & \\
\hline
\end{tabular}

Table 5 Features of Scars Postoperatively

\begin{tabular}{|l|c|c|}
\hline Scar & Number of Patients $(\mathbf{n}=\mathbf{4 6})$ & Percentage (\%) \\
\hline Good & 22 & 47.8 \\
Contracture & 10 & 21.7 \\
Keloid & 14 & 30.5 \\
Total & 46 & 100 \\
\hline
\end{tabular}

our study, this rate was $52.2 \%$ (24/46 patients). Kapucu et al stressed on two issues that need attention when shaping the cleft lip: the first is the lip-reshaping technique; the second is adequate follow-up and care after surgery. National and international authors agree that if complications after surgery are prevented, a sufficient healing result will be achieved. ${ }^{12}$

\section{Deformed Nose}

Nasal deformity usually occurs with lip deformity and is proportional to the severity of lip deformity. This is a general observation of surgeons who perform cleft lip surgery and repair lip and nose deformities after surgery.

Defects in the upper part of the nostrils were found in $78.3 \%$ of patients after cleft lip surgery. In essence, this deformity occurs because the transverse nasal muscles do not fully attach to the anterior nasal cartilage, leading to incorrect positioning of the medial cartilage. However, the deformity can also occur due to the surgeon's improper interference with the soft triangle region, which is not supported by cartilage, and the connection point between the lateral column and middle column. ${ }^{5}$

Our research topic was unilateral cleft lip, so short columella only appeared in 6 patients (13\%). The short columella is typical of bilateral cleft lip and is less commonly seen in unilateral cleft lip; however, it can appear shorter due to displacement of the nasal cartilage. The length of the columella is the basis for nose symmetry. If the Millard method is applied in the primary surgery, the C flap is possible to connect to the incision of the columella. ${ }^{13}$

This study was conducted on Vietnamese subjects, according to reference of international documents and Motier's classification, most children with Cleft lip have these problems postoperative. ${ }^{6}$ 


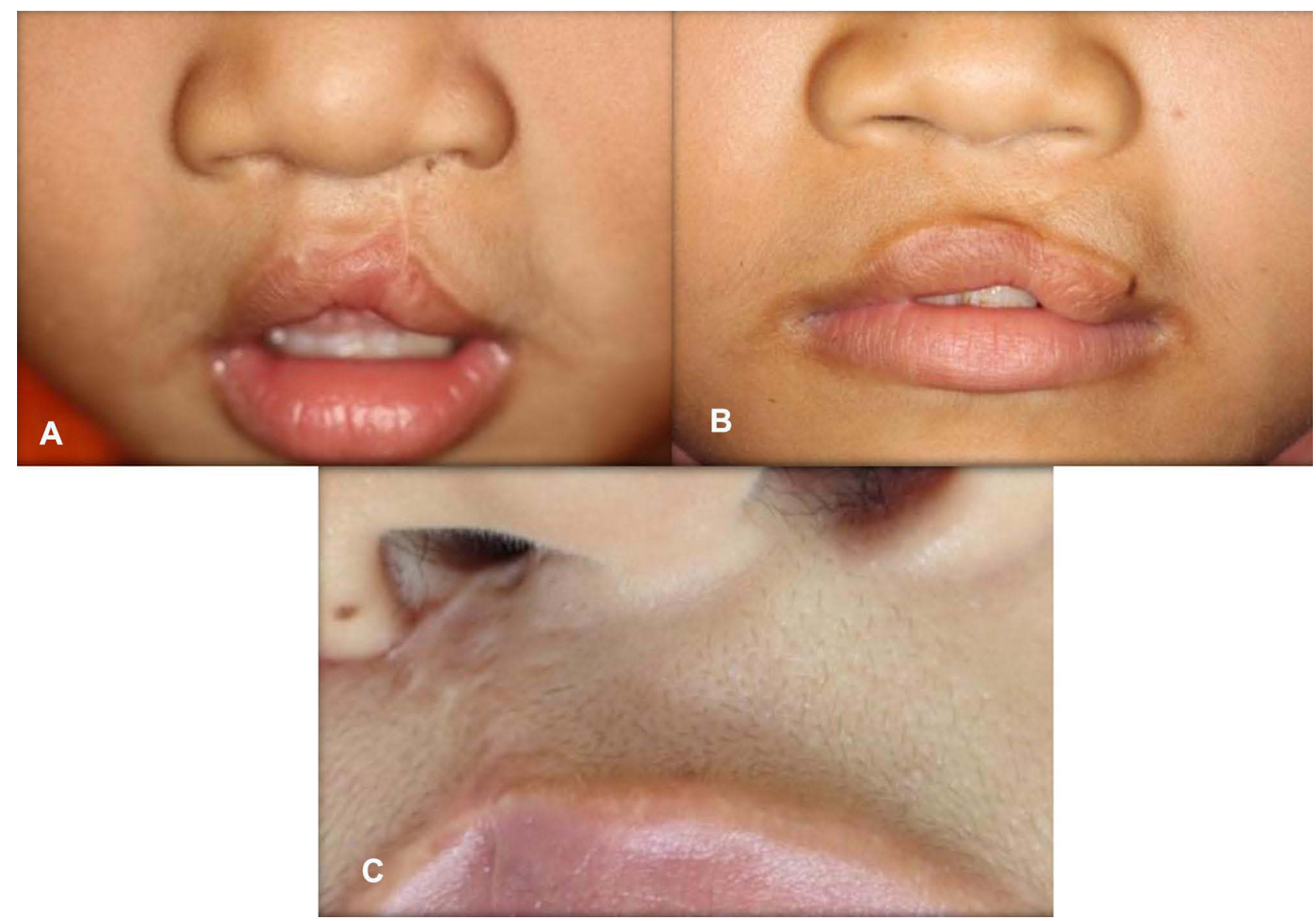

Figure 6 These images illustrate scar revisions. (A) Contracture, (B) Good, (C) Keloid.

\section{Relationship Between Surgical Methods and Deformity of Lip and Nose}

The results of lip and nose deformities differed depending on the first surgical method used. The most commonly

\section{Table 6 Nasal Deformities}

\begin{tabular}{|l|c|c|}
\hline Feature & $\begin{array}{c}\text { Number } \\
\text { of Patients } \\
\text { (n = 46) }\end{array}$ & Percentage (\%) \\
\hline Short columella & 6 & 13.0 \\
Deviation of nasal septum & 36 & 78.3 \\
Narrow nostril & 24 & 52.2 \\
Wide nostril & 0 & 0 \\
Wide subnasale & 0 & 0 \\
Narrow subnasale & 0 & 0 \\
Slight curl of ala of nose & 16 & 26.1 \\
Excessive curl of ala of nose & 0 & 0 \\
Defect of superior nostril contour & 36 & 78.3 \\
High ala of nose & 4 & 8.7 \\
Low ala of nose & 22 & 47.8 \\
Hyotrophic and flat ala of nose & 2 & 4.3 \\
\hline
\end{tabular}

used method was the Millard method in 26 patients (56.5\%), followed by the Tennison method in 16 patients (34.8\%), and the Veau method in 4 patients $(8.7 \%)$. Of the 26 patients who underwent surgery by the Millard method, 8 received very good results $(30.8 \%) ; 16$, good results $(61.5 \%)$; and 2 , acceptable results. The 8 patients who underwent surgery by the Tennison method showed good results. All 4 patients who underwent surgery using the Veau method received very good results.

In Zaleckas et al's research (2011), 19 patients underwent surgery by the Tennison method and 20 patients by the Millard method. The results of this study showed that the differences in average scores of the red lips, scars, or nose between the Tennison and Millard methods were not statistically significant. However, the average lip-skin height score of the Tennison method was significantly higher than that of the Millard method. ${ }^{11}$

According to us and other authors, the advantage of the Tennison method is that it compensates for good lip height, while the Millard method compensates for lip 
Table 7 Results of the First Surgery and Methods

\begin{tabular}{|c|c|c|c|c|c|c|c|}
\hline Method & Excellent & Very Good & Good & Acceptable & Hard to Accept & Total & Percentage (\%) \\
\hline Veau & 0 & 4 & 0 & 0 & 0 & 4 & 8.7 \\
\hline Tennison & 0 & 0 & 16 & 0 & 0 & 16 & 34.8 \\
\hline Millard & 0 & 8 & 16 & 2 & 0 & 26 & 56.5 \\
\hline Total & 0 & 12 & 32 & 2 & 0 & 46 & 100 \\
\hline $\mathrm{P}$-value & \multicolumn{7}{|c|}{$P=0.0452$} \\
\hline
\end{tabular}

deficit in width. The Veau method only applies to patients with a narrow cleft. Researches show that there is no single method of Cleft Lip Surgery that gives perfect results. ${ }^{6}$ Therefore, in clinical practice, considering the complexity of the cleft lip and the advantages and disadvantages of each method, the results of the study help clinicians choose a combination of methods to bring optimal results for each patient.

Moreover, in order to limit these malformations, early reshaping intervention (eg, when NAM - nasal alveolar molting) is needed pre and postoperative, as well as choosing the appropriate surgical method for each case.

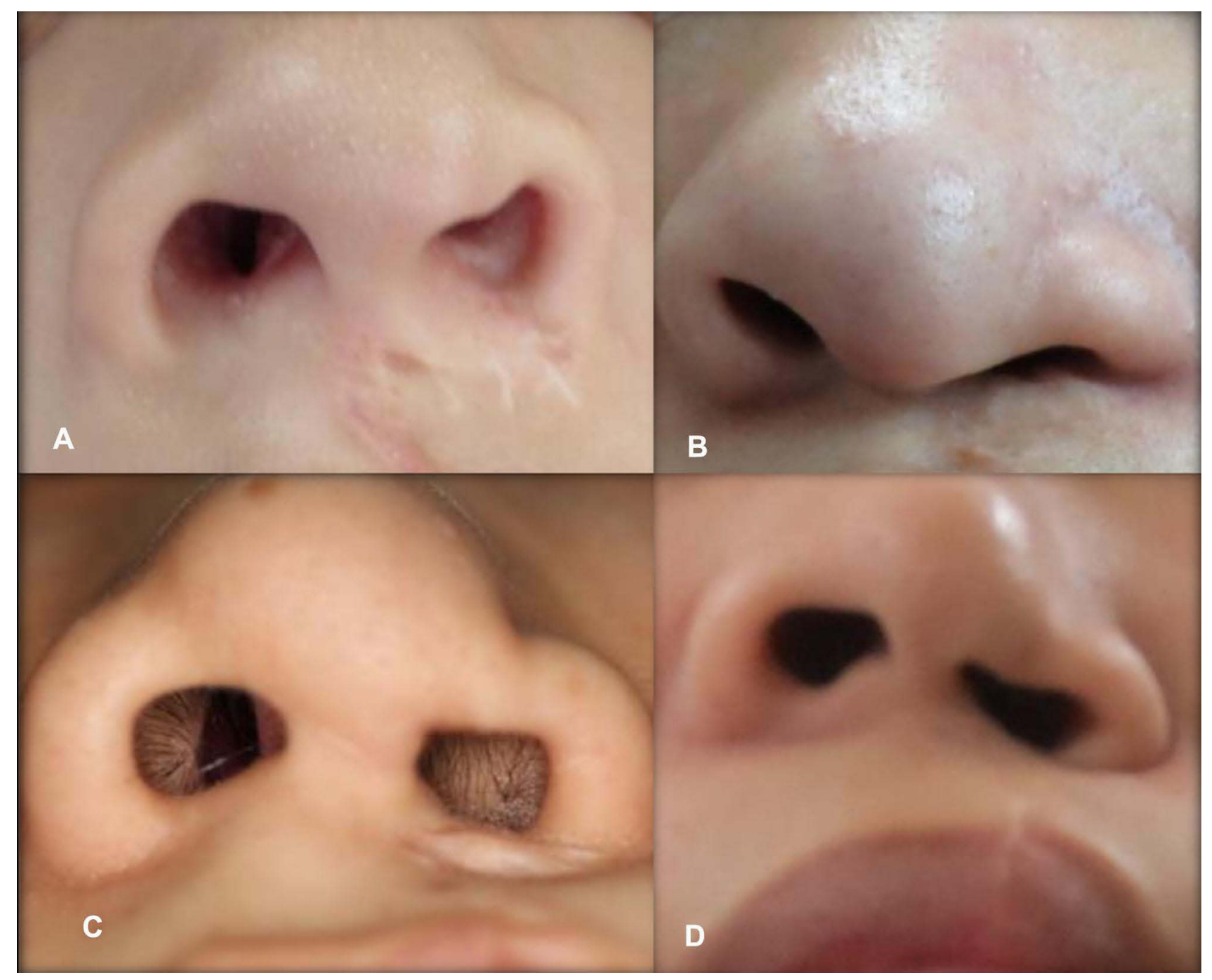

Figure 7 These images illustrate nose deformities. (A) Defect of superior nostril contour; (B) Hypotrophic and flat ala of nose; (C) Narrow nostril, short columella; (D) Deviation of nasal septum, slight curl of ala of nose, narrow nostril. 
Table 8 Comparison of Labial Skin Deformity Results with Other Authors' Results

\begin{tabular}{|l|c|c|c|}
\hline Evaluation & $\begin{array}{c}\text { Rajanikanth } \\
\text { B.R et } \text { al }^{6} \\
(\mathbf{2 0 I 2 )}\end{array}$ & $\begin{array}{c}\text { Cheema S.A } \\
\text { và Asim } \\
\mathbf{M}^{\mathbf{7}} \mathbf{( 2 0 I 4 )}\end{array}$ & $\begin{array}{c}\text { Our } \\
\text { Results } \\
\mathbf{( 2 0} \text { I 8) }\end{array}$ \\
\hline Too short & $10(25 \%)$ & $119(63 \%)$ & $32(34,8 \%)$ \\
Too long & $2(5 \%)$ & $5(3 \%)$ & 0 \\
M. orbiscularis oris deficit & 0 & 0 & 0 \\
Narrow cupidon bow & 0 & $5(3 \%)$ & 0 \\
and philtrim & 0 & 0 & 0 \\
Wide cupidon bow and & 40 & 189 & 46 \\
philtrim & & & \\
Total patients & & & 0 \\
\hline
\end{tabular}

Table 9 Scar Comparison with Other Authors' Results

\begin{tabular}{|l|c|c|c|}
\hline Evaluation & $\begin{array}{c}\text { Rajanikanth } \\
\text { B.R et al } \\
\text { (20I2) }\end{array}$ & $\begin{array}{c}\text { Cheema S. } \\
\text { A, Asim } \\
\mathbf{M}^{\mathbf{7}} \mathbf{( 2 0 1 4 )}\end{array}$ & $\begin{array}{c}\text { Our } \\
\text { Results } \\
\mathbf{( 2 0 1 8 )}\end{array}$ \\
\hline Normal & $28(70 \%)$ & $39(21 \%)$ & $22(47.8 \%)$ \\
Contracture & $6(15 \%)$ & $150(79 \%)$ & $10(21.7 \%)$ \\
Keloid & $6(15 \%)$ & & $14(30.4 \%)$ \\
Total patients & 40 & 189 & 46 \\
\hline
\end{tabular}

\section{Conclusion}

Deformity of the lip and nose after primary unilateral cleft lip repair surgery is inevitable The vermilion notch and lip contour deviation are the two most common secondary deformities of the red lip in our study, followed by thickening and thinning of lips. In addition, deformities of the nose, including nasal septal deviation and defects on the edge of the nostril, also persist. Therefore, it is necessary to have a plan to repair these deformities with a subsequent surgery.

\section{Compliance with Ethical Standards}

The study complied with the Declaration of Helsinki Ethical Principles for Medical Research.

\section{Ethical Approval and Consent to Participate}

Ethical approval was obtained from the institutional review board of Hue Central Hospital with IEC number 08-2018/NCKH-BVH. Written informed consent was taken from each participant and data collection was done after they signed for the consent. Moreover, informed consent was taken from parents or legal guardians for pediatric patients.

\section{Funding}

This research is not funded by any organization.

\section{Disclosure}

The authors report no conflicts of interest in this work.

\section{References}

1. Nguyen VT, Nguyen HL, Nguyen T, Jagomagi T. Oral health status of patients with repaired cleft lip and palate in central Vietnam. Oral Health Prev Dent. 2019;17(5):457-463.

2. Tatum SA. Pediatric facial plastic and reconstructive surgery. Facial Plast Surg Clin North Am. 2014;22(4):xiii. doi:10.1016/j.fsc.20 14.08.004

3. Mulliken JB, Martinez-Perez D. The principle of rotation advancement for repair of unilateral complete cleft lip and nasal deformity: technical variations and analysis of results. Plast Reconstr Surg. 1999;104(5):1247-1260. doi:10.1097/00006534-199910000-00003

4. Kernahan DA. The striped Y--a symbolic classification for cleft lip and palate. Plast Reconstr Surg. 1971;47(5):469-470. doi:10.1097/ 00006534-197105000-00010

5. Mortier PB, Martinot VL, Anastassov Y, Kulik JF, Duhamel A, Pellerin PN. Evaluation of the results of cleft lip and palate surgical treatment: preliminary report. Cleft Palate Craniofac J. 1997;34 (3):247-255. doi:10.1597/1545-1569_1997_034_0247_eotroc_2.3.co_2

6. Rajanikanth BR, Rao KS, Sharma SM, Rajendra Prasad B. Assessment of deformities of the lip and nose in cleft lip alveolus and palate patients by a rating scale. J Maxillofac Oral Surg. 2012;11 (1):38-46. doi:10.1007/s12663-011-0298-6

7. Cheema SA, Asim M. An analysis of deformities in revision surgeries for secondary unilateral cleft lip. J Coll Physicians Surg Pak. 2014;24(9):666-669.

8. Christofides E, Potgieter A, Chait L. A long term subjective and objective assessment of the scar in unilateral cleft lip repairs using the Millard technique without revisional surgery. J Plast Reconstr Aesthet Surg. 2006;59(4):380-386. doi:10.1016/j.bjps.2005.04.037

9. Adetayo AM, Adetayo MO, Adeyemo WL, James OO, Adeyemi MO. Unilateral cleft lip: evaluation and comparison of treatment outcome with two surgical techniques based on qualitative (subject/guardian and professional) assessment. J Korean Assoc Oral Maxillofac Surg. 2019;45(3):141-151. doi:10.5125/jkaoms.2019.45. 3.141

10. Martins DM, Martins JL. Surgical treatment in unilateral cleft lip-nose patients: long-term follow-up using a personal approach based on rose and spina techniques. J Craniofac Surg. 2003;14 (5):797-799.

11. Zaleckas L, Linkeviciene L, Olekas J, Kutra N. The comparison of different surgical techniques used for repair of complete unilateral cleft lip. Medicina. 2011;47(2):85-90. doi:10.3390/medicina470 20011

12. Kapucu MR, Gursu KG, Enacar A, Aras S. The effect of cleft lip repair on maxillary morphology in patients with unilateral complete cleft lip and palate. Plast Reconstr Surg. 1996;97(7):1371-1375; discussion 1376-1378. doi:10.1097/00006534-199606000-00007

13. Anastassov Y, Chipkov C. Analysis of nasal and labial deformities in cleft lip, alveolus and palate patients by a new rating scale: preliminary report. J Craniomaxillofac Surg. 2003;31(5):299-303. doi:10.10 16/S1010-5182(03)00054-4 


\section{Publish your work in this journal}

Clinical, Cosmetic and Investigational Dentistry is an international, peer-reviewed, open access, online journal focusing on the latest clinical and experimental research in dentistry with specific emphasis on cosmetic interventions. Innovative developments in dental materials, techniques and devices that improve outcomes and patient satisfaction and preference will be highlighted. The manuscript management system is completely online and includes a very quick and fair peer-review system, which is all easy to use. Visit http://www.dovepress.com/testimonials.php to read real quotes from published authors. 